\title{
Photocatalytic Properties of Size-Controlled Titania Nanotube Arrays
}

\author{
Takeshi Hashishin, ${ }^{1}$ Keisuke Misawa, ${ }^{2}$ Kazuo Kojima, ${ }^{1}$ Chihiro Yogi, ${ }^{2}$ and Jun Tamaki ${ }^{1}$ \\ ${ }^{1}$ Department of Applied Chemistry, College of Life Sciences, Ritsumeikan University, Shiga 525-8577, Japan \\ ${ }^{2}$ Graduate School of Science and Engineering, Ritsumeikan University, Shiga 525-8577, Japan \\ Correspondence should be addressed to Takeshi Hashishin, hasisin@sk.ritsumei.ac.jp
}

Received 20 February 2011; Revised 16 June 2011; Accepted 22 June 2011

Academic Editor: Abel César Chialvo

Copyright (c) 2011 Takeshi Hashishin et al. This is an open access article distributed under the Creative Commons Attribution License, which permits unrestricted use, distribution, and reproduction in any medium, provided the original work is properly cited.

\begin{abstract}
The titania nanotube arrays (TNAs) with smooth surface was synthesized by anodization of titanium foil with $3 \mathrm{~cm}^{2}$ in square area using the electrolyte composed of $0.2 \mathrm{wt} \% \mathrm{NH}_{4} \mathrm{~F}$ and $0.5 \mathrm{vol} \% \mathrm{H}_{2} \mathrm{SO}_{4}$ in ethylene glycol in order to evaluate the methylene blue photodegradation under ultra-violet irradiation. The tube length and inner diameter as a size parameter were controlled by the anodization time from 5 to $10 \mathrm{~h}$ and applied voltage from 10 to $50 \mathrm{~V}$. The titania nanotube arrays (TNAs) annealed at 300 to $500^{\circ} \mathrm{C}$ were assigned to anatase phase, and TNAs at $600^{\circ} \mathrm{C}$ had both phase of anatase and rutile. The crystallite size and the apparent rate constant were increased with the increase in the annealing temperature of TNAs from 300 to $500^{\circ} \mathrm{C}$. The bigger crystallite size of TNAs is suggested to be related to the increase in the amount of hole at the valence band, leading to the decrease in the apparent rate constant of $\mathrm{MB}$ degradation. Interestingly, the four kinds of linear relationship with the apparent rate constant were seen in both the inner diameter of TNAs and the length. Consequently, the apparent rate constant strongly depended on inner diameter of TNAs.
\end{abstract}

\section{Introduction}

Titanium oxide nanotube arrays prepared in an aqueous solution containing 0.5 to $3.5 \mathrm{wt} \%$ hydrofluoric acid by anodic oxidation were first reported by Gong et al. [1] The nanotube arrays with opened tops and closed bottom are desirable for applications due to their large surface areas and high reactivities. Recently, Roy et al. [2] and Rani et al. [3] reported the key functional features of titania nanotubes such as their growth, modification, and properties in the hundred articles related to electrochemically self-assembled titania nanotube arrays. The potential of their applications has therefore been evident for the wide fields: gas sensors [4-7], water photoelectrolysis [8-14], dye-sensitized and solid-state heterojunction solar cells [15-21], and biomedical materials [22].

Anodized titania nanotube arrays have been synthesized in many different electrolytes: aqueous and organic solutions, and acidic and neutral ones, all of which contains fluoride ions [1, 23-26]. In a HF-based aqueous electrolyte, which has been the most frequently reported, nanotube growth has been limited up to a length of only $500 \mathrm{~nm}$ due to the strong chemical dissolution property of the titania layer into the solution; the titania film anodized at more than $30 \mathrm{~V}$ had no tube arrays structure $[27,28]$. Recently, some neutral electrolytes have been used to fabricate longer titania nanotube arrays $[26,29,30]$. The neutral solutions, as a mild anodic oxidizing reactant, essentially suppress the chemical dissolution of the oxidized titania compared with acidic aqueous solutions [30]. Paulose et al. reported that a nanotube length of about $200 \mu \mathrm{m}$ was obtained at $60 \mathrm{~V}$ by using an electrolyte composed of $\mathrm{NH}_{4} \mathrm{~F}$, water, and ethylene glycol; however, a $200 \mu \mathrm{m}$ thick nanotube array film tended to peel off from the titanium substrate after drying in air due to the surface tension of water acting on the interface between the film and the substrate [26]. Thus, long nanotube arrays are unstable when dried in air. For many engineering applications, titania nanotube arrays require physical stability against drying or annealing; therefore, controlling the nanotube length is important. A free-standing titania 
nanotube layers with both ends open and a smooth surface were developed by applied voltage transition from 60 to $120 \mathrm{~V} \mathrm{[31];} \mathrm{however,} \mathrm{there} \mathrm{was} \mathrm{no} \mathrm{information} \mathrm{on} \mathrm{film}$ thickness of the nanotube layer.

There are only limited publications on the effect of the morphology of titania nanotube arrays on photocatalytic behavior $[32,33]$. These reports showed the advantage over sol-gel films and the effects of crystallinity, tube length, and wall thickness on the degradation of dye aqueous solutions; however, the effect on the inner diameter was not specified.

In the present work, we succeeded in preparation of the TNAs with no peeling off from the growth substrate of them, which were synthesized at $50 \mathrm{~V}$ for $5 \mathrm{~h}$ in an electrolyte composed of $0.2 \mathrm{wt} \% \mathrm{NH}_{4} \mathrm{~F}$ and $0.5 \mathrm{Vol} \% \mathrm{H}_{2} \mathrm{SO}_{4}$ in ethylene glycol. It was also possible to adjust the tube length and inner diameter by controlling the anodization time and applied voltage. Furthermore, the effects of annealing temperature of TNAs and size parameters of the tube length, the inner diameter, and the wall thickness on the degradation of methylene blue in aqueous solution were also investigated in detail.

\section{Experimental Procedure}

The titania nanotube arrays (TNAs) were synthesized from titanium foil with $0.3 \mathrm{~mm}$ thick (99.5\% purity; Nilaco). Anodization was conducted at room temperature using the titanium foil as anode and an aluminum foil as cathode in an electrolyte solution of $0.2 \mathrm{wt} \% \mathrm{NH}_{4} \mathrm{~F}$ and 0.5 vol $\% \mathrm{H}_{2} \mathrm{SO}_{4}$ in ethylene glycol. A DC power of $10-50 \mathrm{~V}$ was supplied for $5-10 \mathrm{~h}$ to drive the anodization. The TNAs synthesized were sonicated in ethanol, dried in air and then annealed at 300 to $600^{\circ} \mathrm{C}$ for $6 \mathrm{~h}$. The morphological features of the TNAs anodized were observed by means of FE-SEM (Hitachi S-4800), and their structural changes on annealing temperature were confirmed by means of X-ray diffraction (XRD, Rigaku RINT/DMAX-2200 X-ray diffractometer with $\mathrm{Cu}-\mathrm{K} \mu$ radiation). The photocatalytic properties of the TNAs obtained in different anodization and annealing conditions were evaluated from the photodegradation behavior of a methylene blue (MB) dye in aqueous solution. These TNAs were immersed in an $\mathrm{MB}$ solution $\left(1.63 \times 10^{-5} \mathrm{M}, 3.5 \mathrm{~mL}\right)$ which had been placed in a quartz cell $\left(10 \times 10 \times 65 \mathrm{~mm}^{3}\right)$, and then, irradiated by a UV lamp $\left(365 \mathrm{~nm}, 60 \mu \mathrm{W} \mathrm{cm} \mathrm{cm}^{-2}\right)$ at $25^{\circ} \mathrm{C}$. The solution was purged with oxygen for $60 \mathrm{~min}$ prior to UV irradiation, and the purging continued during irradiation. The degradation of $\mathrm{MB}$ dye was monitored by absorbance at around $600-650 \mathrm{~nm}$ on a UV-Vis spectrometer (Shimadzu, UV-1700).

\section{Results and Discussion}

Since Zhang et al. [34] predicted two theories of kinetics of growth of anodic oxide films: the high field model (HFM) and the point defect model (PDM), the actual model of TNAs has been developed to explain the formation mechanism of TNAs based on anionic species containing fluoride ion, proton, and their complex, as discussed in many papers of

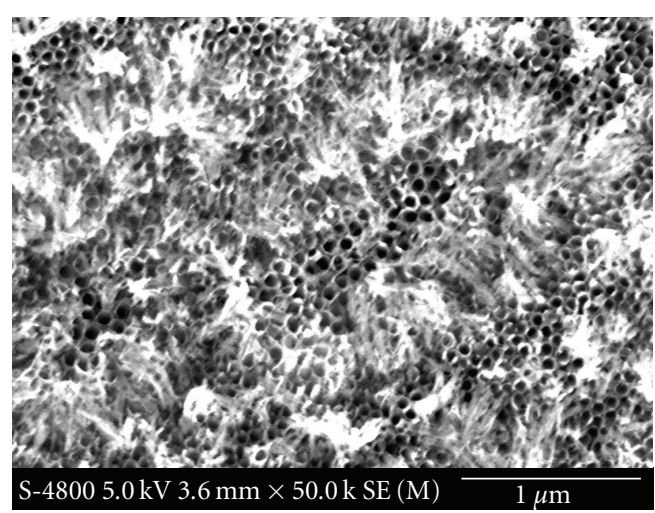

(a)

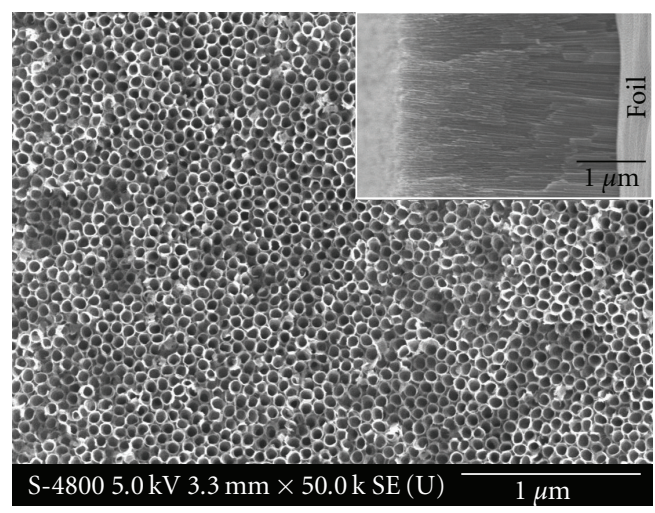

(b)

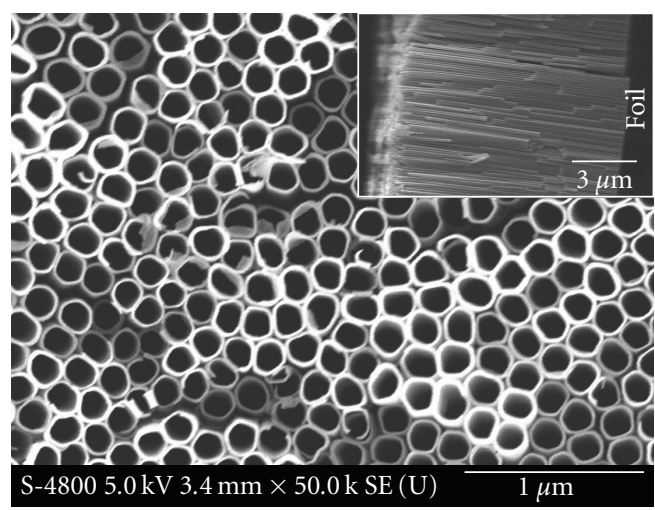

(c)

FIGURE 1: FE-SEM images of titania nanotube arrays (TNAs) formed by anodization for $5 \mathrm{~h}$ in electrolyte solutions: (a) without $\mathrm{H}_{2} \mathrm{SO}_{4}$ at $20 \mathrm{~V}$, (b) with $\mathrm{H}_{2} \mathrm{SO}_{4}$ at $20 \mathrm{~V}$, and (c) with $\mathrm{H}_{2} \mathrm{SO}_{4}$ at $50 \mathrm{~V}$. Insets show cross-sectional images.

Grimes et al. and Schmuki et al. listed in Section 1. In the present work, the $\mathrm{NH}_{4} \mathrm{~F}-\mathrm{H}_{2} \mathrm{SO}_{4}$-EG system was chosen as an electrolyte suitable for the tube structure with smooth surface, in order to examine the results for the photocatalytic degradation of methylene blue using TNAs.

Figure 1 shows the typical surface morphologies and cross-sections of TNAs formed by anodization for $5 \mathrm{~h}$ using an electrolyte with/without $0.5 \mathrm{vol} \%$ sulfuric acid. The array 


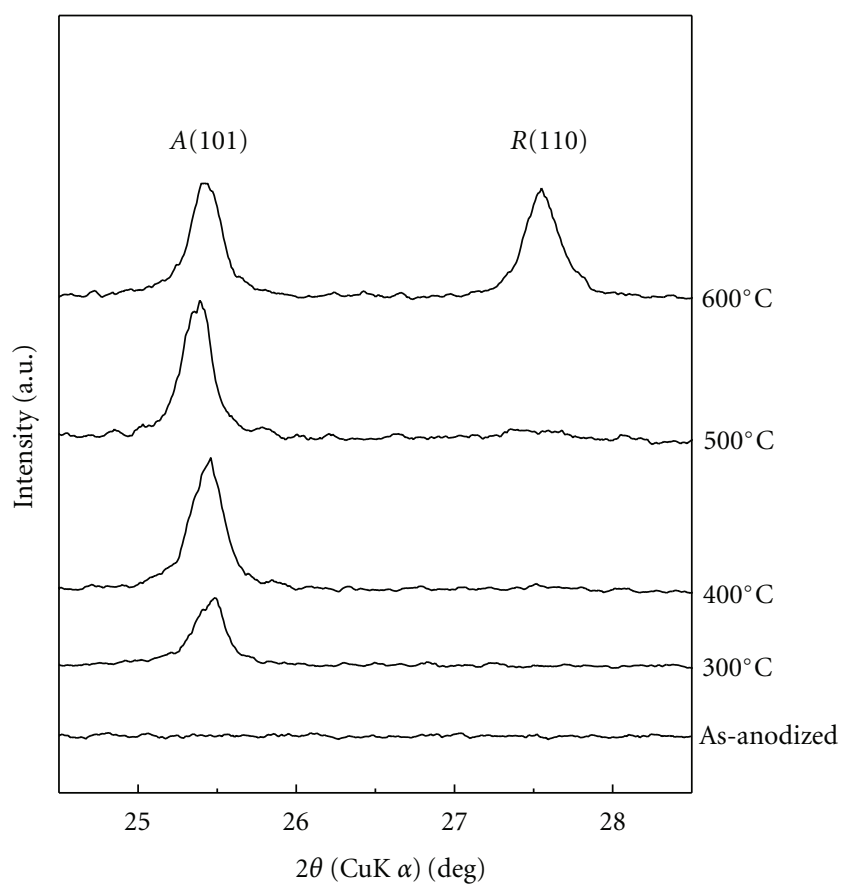

(a)

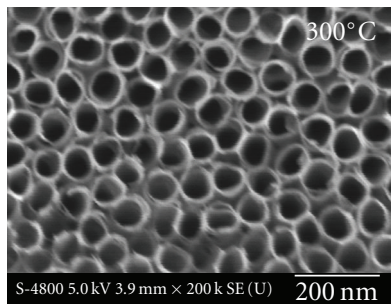

(b)

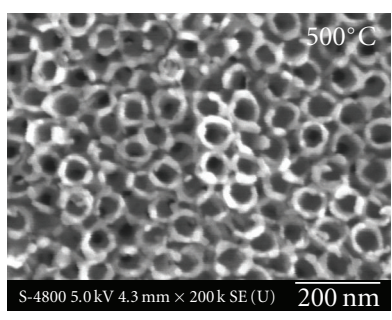

(d)

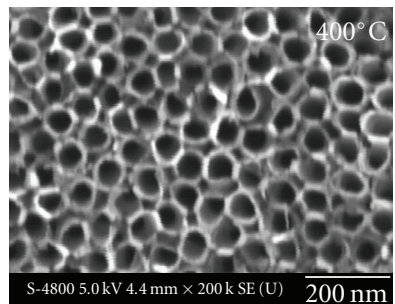

(c)

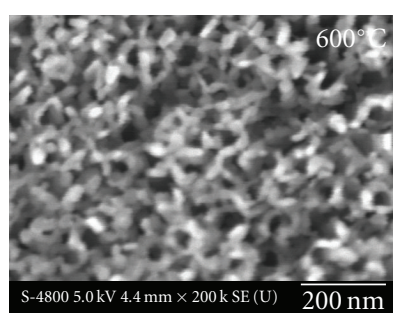

(e)
FIGURE 2: The titania nanotube arrays (TNAs) of as-anodized and annealed at 300 to $600^{\circ} \mathrm{C}$ : (a) X-ray diffraction patterns; (b,c,d,e) surface morphologies.

was vertically aligned to the titanium foil and was covered with entangled oxide layers fabricated by anodization in an electrolyte without $\mathrm{H}_{2} \mathrm{SO}_{4}$ as seen in Figure 1(a). On the other hand, the addition of 0.5 vol $\% \mathrm{H}_{2} \mathrm{SO}_{4}$ to the ethylene glycol solution was responsible for the surface smoothness of the nanotube array as shown in Figure 1(b). As observed from these figures, the surface morphology was affected by the concentration of proton, as discussed by Cai et al. [28] and Yin et al. [35].

Figures 1(b) and 1(c) show that increasing the applied voltage from 20 to $50 \mathrm{~V}$ increased the inner diameter of

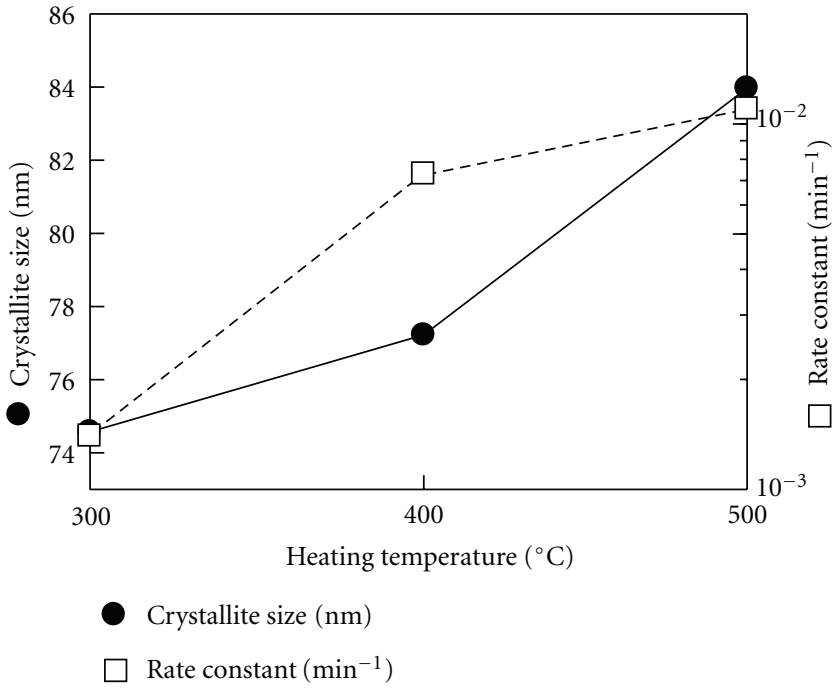

(a)

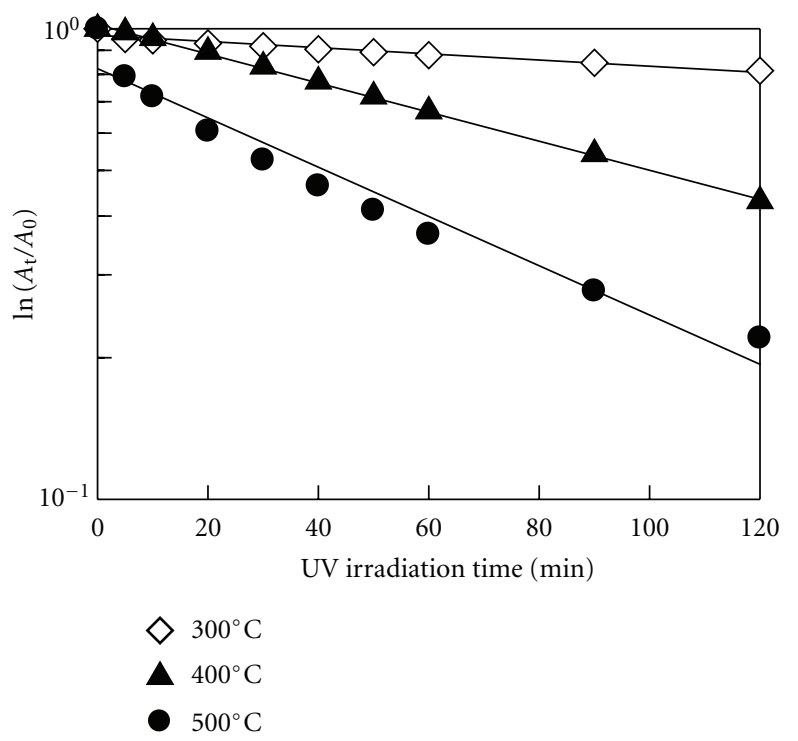

(b)

FIGURE 3: Effects of annealing temperature of the titania nanotube arrays (TNAs) anodized at $20 \mathrm{~V}$ for $5 \mathrm{~h}$ (a) on the crystallite size of (101) diffraction peak and the rate constant, that is, the slope of (b), and (b) on the change of MB concentration as a $\ln \left(A_{t} / A_{0}\right)$ (at $365 \mathrm{~nm}$ ) with ultra-violet irradiation time.

the resulting nanotube array from 37.3 to $110.3 \mathrm{~nm}$ by anodization for $5 \mathrm{~h}$. As shown in the insets, longer nanotube array can be formed at $50 \mathrm{~V}$; the tube length also increased from 3.5 to $12.7 \mu \mathrm{m}$. The size parameters of the TNAs anodized at $10-50 \mathrm{~V}$ for $5 \mathrm{~h}$, tube length, inner diameter, wall-thickness, were measured using the scale bar of SEM images. From the linear least squares fitting of these parameters, the correlation between the size parameters and applied voltage was calculated, showing the ratio of $321 \mathrm{~nm} / \mathrm{V}$ in length, $2.33 \mathrm{~nm} / \mathrm{V}$ in inner diameter, and $0.334 \mathrm{~nm} / \mathrm{V}$ in wallthickness. The growth rate for the TNAs anodized at $50 \mathrm{~V}$ 


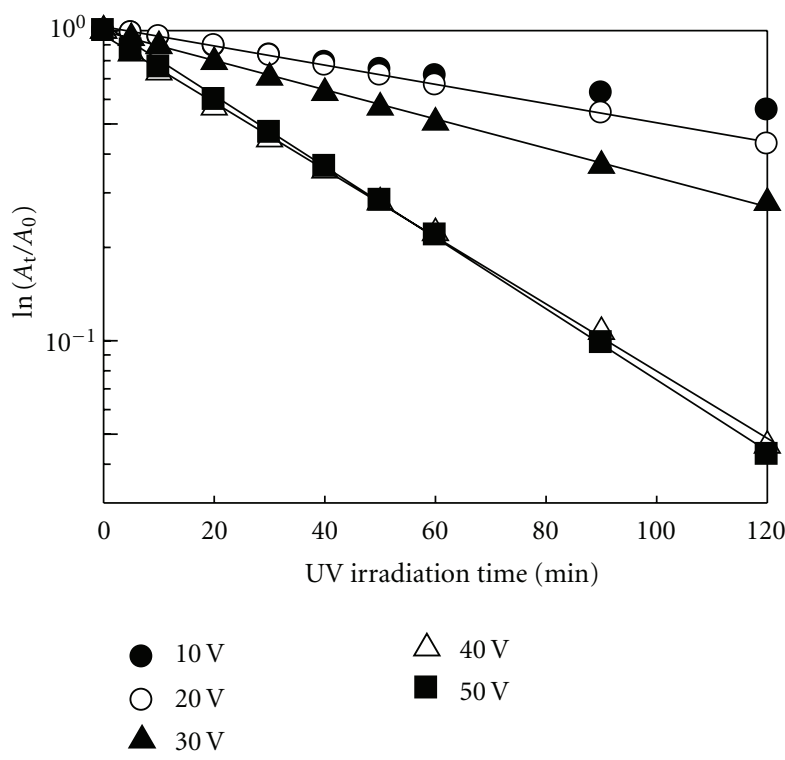

(a)

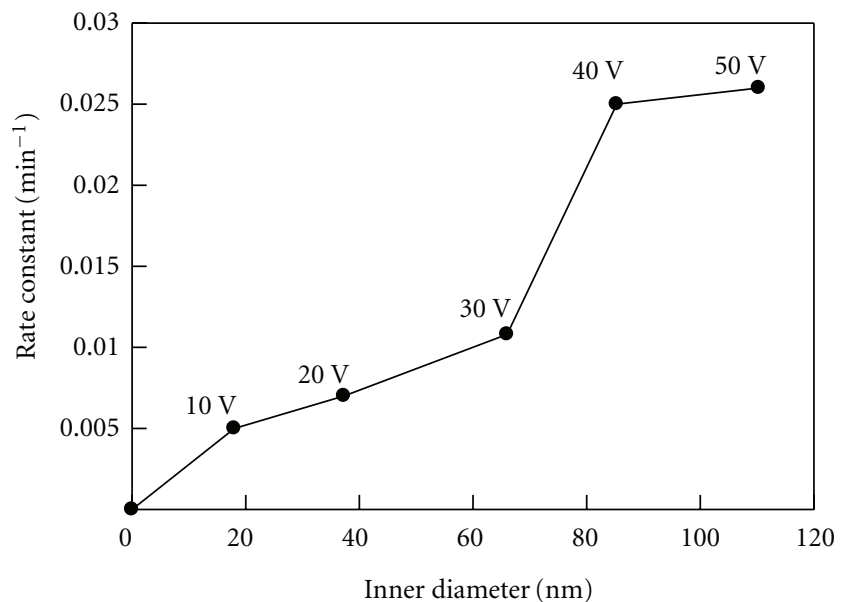

(b)

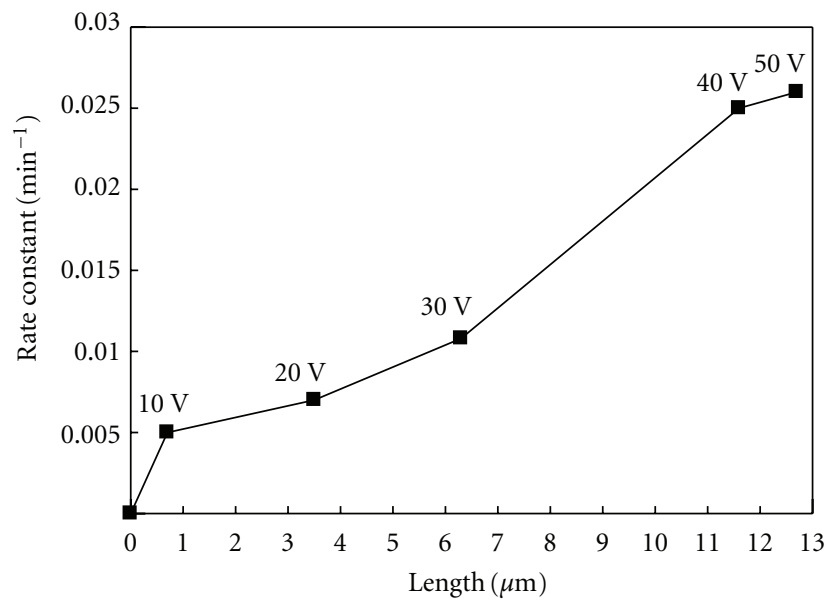

(c)

FIGURE 4: Effects of the applied voltage of titania nanotube arrays (TNAs) anodized for $5 \mathrm{~h}(\mathrm{a})$ on the degree of MB degradation as a $\ln \left(A_{t} / A_{0}\right)$ (at $365 \mathrm{~nm}$ ) with ultra-violet irradiation time, (b) on the correlation between the inner diameter and the apparent rate constant, that is, the slope of (a), and (c) on the apparent rate constant as a function of the length. The size and electric field factors of TNAs for the apparent rate constant of respective voltage regions are summarized in Table 1.

for $5-10 \mathrm{~h}$ was $100 \mathrm{~nm} / \mathrm{h}$ in length and $8.5 \mathrm{~nm} / \mathrm{h}$ in inner diameter.

Figure 2 shows the X-ray diffraction (XRD) patterns and scanning electron microscopy (SEM) images of TNAs annealed at 300 to $600^{\circ} \mathrm{C}$. The TNAs annealed at 300 to $500^{\circ} \mathrm{C}$ were assigned to anatase phase of $\mathrm{TiO}_{2}(a=0.379 \mathrm{~nm}$, $c=0.951 \mathrm{~nm}$; JSPDS 21-1272), and TNAs at $600^{\circ} \mathrm{C}$ had both phase of anatase and rutile ( $a=0.459 \mathrm{~nm}, c=0.296 \mathrm{~nm}$; JCPDS 21-1276), as shown in Figure 2(a). The respective tube wall-thickness of TNAs annealed at 300 and $400^{\circ} \mathrm{C}$ indicated 4.2 and $5.5 \mathrm{~nm}$, which was calculated from the SEM images of Figures 2(b) and 2(c). The tube wall-thickness at $500^{\circ} \mathrm{C}, 8.5 \mathrm{~nm}$, from Figure $2(\mathrm{~d})$, showed initiation of the particle formation of the tube wall. On the other hand, the heat treatment at $600^{\circ} \mathrm{C}$ enlarged the tube wall-thickness from 8.5 to $13.2 \mathrm{~nm}$. As the result, the tube structure was collapsed completely. The crystallite size $(D)$ of TNAs annealed at 300 to $600^{\circ} \mathrm{C}$ was calculated from anatase 101 diffraction peak using Scherrer equation $(D=K \lambda / \beta \cos \theta$; $K=0.9$ ), as shown in Figure 3(a). The $D$ value of TNAs annealed at $600^{\circ} \mathrm{C}$, ca. $80 \mathrm{~nm}$, was smaller than that of TNAs at $500^{\circ} \mathrm{C}$, ca. $84 \mathrm{~nm}$. This behavior of crystallite size is similar to the temperature dependence of the anatase reported by Varghese et al. [36]. The lattice became 1.2fold increasing in a-axis and 3.2-fold decreasing in c-axis by phase transition from anatase to rutile, leading to collapse the tubular structure. The effects of annealing temperature of TNAs from 300 to $500^{\circ} \mathrm{C}$ on the photocatalytic degradation of methylene blue (MB) are shown in Figure 3(b). From the linear least squares fitting of plots in Figure 3(b), it was 
obvious that the photodegradation of the MB obeys nearly the first-order reaction kinetics; $\ln \left(A_{t} / A_{0}\right)=-k t$. From the slope of the linear fitting, the apparent rate constant of $\mathrm{MB}$ degradation was evaluated as $0.0014 \mathrm{~min}^{-1}\left(300^{\circ} \mathrm{C}\right)$, $0.0073 \mathrm{~min}^{-1}\left(400^{\circ} \mathrm{C}\right)$, and $0.011 \mathrm{~min}^{-1}\left(500^{\circ} \mathrm{C}\right)$. These values were plotted in Figure 3(a) according to the right vertical axis. The crystallite size and the apparent rate constant were increased with the increase in the annealing temperature of TNAs. The size dependence of the fluorescence of the surface states in semiconductor nanoparticles indicated that the separation between electron-hole states (similar to the donor-acceptor pairs) increased upon decreasing particle size [37]. Consequently, the bigger crystallite size of TNAs is suggested to be related to the increase in the amount of hole at the valence band of $\mathrm{TiO}_{2}$, leading to the decrease in the apparent rate constant of $\mathrm{MB}$ degradation. The plots of TNAs annealed at $500^{\circ} \mathrm{C}$ were slightly out of line, which depended on initiating the particle formation of the tube wall. Therefore, the TNAs annealed at $400^{\circ} \mathrm{C}$ are adequate for evaluation of $\mathrm{MB}$ photodegradation.

Figure 4(a) shows the correlation between UV irradiation time and the $\mathrm{MB}$ photodegradation of the titania nanotube arrays (TNAs) annealed at $400^{\circ} \mathrm{C}$ for $6 \mathrm{~h}$ after anodized at $10-50 \mathrm{~V}$ for $5 \mathrm{~h}$. The respective plots of the TNAs anodized at $10-50 \mathrm{~V}$ for $5 \mathrm{~h}$ existed on the linear least squares fitting. The apparent rate constant was calculated from the slope of five lines: $0.0050 \mathrm{~min}^{-1}(10 \mathrm{~V}), 0.0071 \mathrm{~min}^{-1}(20 \mathrm{~V}), 0.011 \mathrm{~min}^{-1}$ $(30 \mathrm{~V}), 0.025 \mathrm{~min}^{-1}(40 \mathrm{~V})$, and $0.026 \mathrm{~min}^{-1}(50 \mathrm{~V})$. The effects of the applied voltage of TNAs anodized for $5 \mathrm{~h}$ on the correlation between the inner diameter and the apparent rate constant are shown in Figure 4(b). The apparent rate constant as a function of the length is also plotted in Figure 4(c). Interestingly, the four kinds of linear relationship with the apparent rate constant were seen in both the inner diameter of TNAs and the length, which are categorized as regions $\mathrm{A}$ (0-10 V), B (10-30 V), C (30-40 V), and D (40-50 V). The apparent rate constants at four regions were normalized as the unit of $(\mathrm{min} \cdot \mathrm{mm} \cdot \mathrm{V})^{-1}$ including both factors of size and electric field, as summarized in Table 1. The apparent rate constant strongly depended on inner diameter of TNAs. Especially, the increase of the apparent rate constant was considerable in the slope change from region $\mathrm{B}$ to region C. Generally, the EM wave absorber and dipole antenna for millimeter wave length are designed to correspond with the wave length of $\lambda / 4$, denoting maximum absorbance in the phase difference of 90 degree. The wave length of ultraviolet with maximum absorbance is $365 \mathrm{~nm}$ in this study. The $\lambda / 4$ of UV wave length $(365 \mathrm{~nm})$ is ca. $91 \mathrm{~nm}$. The drastic MB photodegradation appeared at the slope change from region $\mathrm{B}$ (66 nm in I. D.) to region $\mathrm{C}$ ( $85 \mathrm{~nm}$ in I. D.), suggesting that the wave length of $\lambda / 4$ contributed to the efficient generation of hole on the surface of TNAs.

In the previous study, we reported that the maximum absorption peak was blue shifted due to the formation of the demethylated compounds of $\mathrm{MB}$ in the photodegradation process of $\mathrm{MB}$ using titania thin film prepared by sol-gel method $[38,39]$. In the present study, the similar blue shift was confirmed and therefore the demethylation of MB would occur. Five different demethylated compounds such as Azure
TABle 1: The dependence of rate constant on the inner diameter (I. D.) and the length of titania nanotube arrays.

\begin{tabular}{lccc}
\hline Region & $\begin{array}{c}\text { Voltage } \\
(\mathrm{V})\end{array}$ & $\begin{array}{c}k / \mathrm{I} . \mathrm{D} . \\
(\mathrm{min} \cdot \mathrm{mm} \cdot \mathrm{V})^{-1}\end{array}$ & $\begin{array}{c}k / \text { Length } \\
(\mathrm{min} \cdot \mathrm{mm} \cdot \mathrm{V})^{-1}\end{array}$ \\
\hline $\mathrm{A}$ & $0-10$ & 28 & 0.71 \\
$\mathrm{~B}$ & $10-30$ & 6.1 & 0.050 \\
$\mathrm{C}$ & $30-40$ & 74 & 0.27 \\
$\mathrm{D}$ & $40-50$ & 4.0 & 0.091 \\
\hline
\end{tabular}

$\mathrm{B}$, Azure A, N, $\mathrm{N}^{\prime}$-dimethylthionine (the isomer of Azure A), Azure $\mathrm{C}$, and thionine could be formed by the demethylation reaction, but the correlation between these compounds and the morphology of titania nanotube array is still unclear.

\section{Conclusion}

We succeeded in the preparation of the titania nanotube arrays (TNAs) with no peeling off from the growth substrate of them, which in synthesized at $50 \mathrm{~V}$ for $5 \mathrm{~h}$ in an electrolyte composed of $0.2 \mathrm{wt} \% \mathrm{NH}_{4} \mathrm{~F}$ and $0.5 \mathrm{Vol} \% \mathrm{H}_{2} \mathrm{SO}_{4}$ to ethylene glycol. It was also possible to adjust the tube length and inner diameter by controlling the anodization time and applied voltage. The TNAs annealed at 300 to $500^{\circ} \mathrm{C}$ were assigned to anatase phase, and TNAs at $600^{\circ} \mathrm{C}$ had both phase of anatase and rutile. The effects of annealing temperature of TNAs from 300 to $500^{\circ} \mathrm{C}$ on the photocatalytic degradation of methylene blue $(\mathrm{MB})$ were investigated under UV irradiation with $365 \mathrm{~nm}$. The crystallite size and the apparent rate constant were increased with the increase in the annealing temperature of TNAs from 300 to $500^{\circ} \mathrm{C}$. The bigger crystallite size of TNAs is suggested to be related to the increase in the amount of hole at the valence band of $\mathrm{TiO}_{2}$, leading to the decrease in the apparent rate constant of $\mathrm{MB}$ degradation. The effects of the applied voltage of TNAs anodized for $5 \mathrm{~h}$ on the correlation between the inner diameter and the apparent rate constant. Interestingly, the four kinds of linear relationship with the apparent rate constant were seen in both the inner diameter of TNAs and the length. As a conclusion, the apparent rate constant strongly depended on inner diameter of TNAs.

\section{Acknowledgment}

This work was supported by a Grant-in-Aid for General Research and Research Promoting Program fromthe Ritsumeikan University Research Funding.

\section{References}

[1] D. Gong, C. A. Grimes, O. K. Varghese et al., "Titanium oxide nanotube arrays prepared by anodic oxidation," Journal of Materials Research, vol. 16, no. 12, pp. 3331-3334, 2001.

[2] P. Roy, S. Berger, and P. Schmuki, " $\mathrm{TiO}_{2}$ nanotubes: synthesis and applications," Angewandte Chemie-International Edition, vol. 50, no. 13, pp. 2904-2939, 2011.

[3] S. Rani, S. C. Roy, M. Paulose et al., "Synthesis and applications of electrochemically self-assembled titania nanotube 
arrays," Physical Chemistry Chemical Physics, vol. 12, no. 12, pp. 2780-2800, 2010.

[4] O. K. Varghese, D. Gong, M. Paulose, K. G. Ong, E. C. Dickey, and C. A. Grimes, "Extreme changes in the electrical resistance of titania nanotubes with hydrogen exposure," Advanced Materials, vol. 15, no. 7-8, pp. 624-627, 2003.

[5] G. K. Mor, M. A. Carvalho, O. K. Varghese, M. V. Pishko, and C. A. Grimes, "A room-temperature $\mathrm{TiO}_{2}$-nanotube hydrogen sensor able to self-clean photoactively from environmental contamination," Journal of Materials Research, vol. 19, no. 2, pp. 628-634, 2004.

[6] O. K. Varghese, G. K. Mor, C. A. Grimes, M. Paulose, and N. Mukherjee, "A titania nanotube-array room-temperature sensor for selective detection of hydrogen at low concentrations," Journal of Nanoscience and Nanotechnology, vol. 4, no. 7, pp. 733-737, 2004.

[7] M. Paulose, O. K. Varghese, G. K. Mor, C. A. Grimes, and K. G. Ong, "Unprecedented ultra-high hydrogen gas sensitivity in undoped titania nanotubes," Nanotechnology, vol. 17, no. 2, pp. 398-402, 2006.

[8] O. K. Varghese, M. Paulose, K. Shankar, G. K. Mor, and C. A. Grimes, "Water-photolysis properties of micron-length highly-ordered titania nanotube-arrays," Journal of Nanoscience and Nanotechnology, vol. 5, no. 7, pp. 1158-1165, 2005.

[9] K. Shankar, G. K. Mor, H. E. Prakasam et al., "Highly-ordered $\mathrm{TiO}_{2}$ nanotube arrays up to $220 \mu \mathrm{m}$ in length: use in water photoelectrolysis and dye-sensitized solar cells," Nanotechnology, vol. 18, no. 6, Article ID 065707, 2007.

[10] G. K. Mor, K. Shankar, M. Paulose, O. K. Varghese, and C. A. Grimes, "Enhanced photocleavage of water using titania nanotube arrays," Nano Letters, vol. 5, no. 1, pp. 191-195, 2005.

[11] G. K. Mor, H. E. Prakasam, O. K. Varghese, K. Shankar, and C. A. Grimes, "Vertically oriented Ti-Fe-O nanotube array films: toward a useful material architecture for solar spectrum water photoelectrolysis," Nano Letters, vol. 7, no. 8, pp. 2356-2364, 2007.

[12] G. K. Mor, O. K. Varghese, R. H. T. Wilke et al., "p-type Cu-Ti$\mathrm{O}$ nanotube arrays and their use in self-biased heterojunction photoelectrochemical diodes for hydrogen generation," Nano Letters, vol. 8, no. 7, pp. 1906-1911, 2008.

[13] K. Shankar, K. C. Tep, G. K. Mor, and C. A. Grimes, "An electrochemical strategy to incorporate nitrogen in nanostructured $\mathrm{TiO}_{2}$ thin films: modification of bandgap and photoelectrochemical properties," Journal of Physics D: Applied Physics, vol. 39, no. 11, pp. 2361-2366, 2006.

[14] M. Paulose, K. Shankar, S. Yoriya et al., "Anodic growth of highly ordered $\mathrm{TiO}_{2}$ nanotube arrays to $134 \mu \mathrm{m}$ in length," Journal of Physical Chemistry B, vol. 110, no. 33, pp. 1617916184, 2006.

[15] G. K. Mor, K. Shankar, M. Paulose, O. K. Varghese, and C. A. Grimes, "Use of highly-ordered $\mathrm{TiO}_{2}$ nanotube arrays in dyesensitized solar cells," Nano Letters, vol. 6, no. 2, pp. 215-218, 2006.

[16] G. K. Mor, K. Shankar, M. Paulose, O. K. Varghese, and C. A. Grimes, "High efficiency double heterojunction polymer photovoltaic cells using highly ordered $\mathrm{TiO}_{2}$ nanotube arrays," Applied Physics Letters, vol. 91, no. 15, 2007.

[17] K. Shankar, G. K. Mor, H. E. Prakasam, O. K. Varghese, and C. A. Grimes, "Self-assembled hybrid polymer- $\mathrm{TiO}_{2}$ nanotube array heterojunction solar cells," Langmuir, vol. 23, no. 24, pp. 12445-12449, 2007.

[18] K. Shankar, J. Bandara, M. Paulose et al., "Highly efficient solar cells using $\mathrm{TiO}_{2}$ nanotube arrays sensitized with a donorantenna dye," Nano Letters, vol. 8, no. 6, pp. 1654-1659, 2008.
[19] O. K. Varghese, M. Paulose, and C. A. Grimes, "Long vertically aligned titania nanotubes on transparent conducting oxide for highly efficient solar cells," Nature Nanotechnology, vol. 4, no. 9, pp. 592-597, 2009.

[20] G. K. Mor, S. Kim, M. Paulose et al., "Visible to near-infrared light harvesting in $\mathrm{TiO}_{2}$ nanotube array-P3HT based heterojunction solar cells," Nano Letters, vol. 9, no. 12, pp. 42504257, 2009.

[21] M. Paulose, K. Shankar, O. K. Varghese, G. K. Mor, and C. A. Grimes, "Application of highly-ordered $\mathrm{TiO}_{2}$ nanotube-arrays in heterojunction dye-sensitized solar cells," Journal of Physics D: Applied Physics, vol. 39, no. 12, pp. 2498-2503, 2006.

[22] S. Liu and A. Chen, "Coadsorption of horseradish peroxidase with thionine on $\mathrm{TiO}_{2}$ nanotubes for biosensing," Langmuir, vol. 21, no. 18, pp. 8409-8413, 2005.

[23] J. M. Macak, L. V. Taveira, H. Tsuchiya, K. Sirotna, J. Macak, and P. Schmuki, "Influence of different fluoride containing electrolytes on the formation of self-organized titania nanotubes by Ti anodization," Journal of Electroceramics, vol. 16, no. 1, pp. 29-34, 2006.

[24] N. R. De Tacconi, C. R. Chenthamarakshan, G. Yogeeswaran et al., "Nanoporous $\mathrm{TiO}_{2}$ and WO3 films by anodization of titanium and tungsten substrates: Influence of process variables on morphology and photoelectrochemical response," Journal of Physical Chemistry B, vol. 110, no. 50, pp. 25347-25355, 2006.

[25] X. Feng, J. M. Macak, and P. Schmuki, "Robust self-organization of oxide nanotubes over a wide $\mathrm{pH}$ range," Chemistry of Materials, vol. 19, no. 7, pp. 1534-1536, 2007.

[26] M. Paulose, L. Peng, K. C. Popat et al., "Fabrication of mechanically robust, large area, polycrystalline nanotubular/porous $\mathrm{TiO}_{2}$ membranes," Journal of Membrane Science, vol. 319, no. 1-2, pp. 199-205, 2008.

[27] J. M. MacAk, K. Sirotna, and P. Schmuki, "Self-organized porous titanium oxide prepared in $\mathrm{Na}_{2} \mathrm{SO} 4 / \mathrm{NaF}$ electrolytes," Electrochimica Acta, vol. 50, no. 18, pp. 3679-3684, 2005.

[28] Q. Cai, M. Paulose, O. K. Varghese, and C. A. Grimes, "The effect of electrolyte composition on the fabrication of selforganized titanium oxide nanotube arrays by anodic oxidation," Journal of Materials Research, vol. 20, no. 1, pp. 230-236, 2005.

[29] H. E. Prakasam, K. Shankar, M. Paulose, O. K. Varghese, and C. A. Grimes, "A new benchmark for $\mathrm{TiO}_{2}$ nanotube array growth by anodization," Journal of Physical Chemistry C, vol. 111, no. 20, pp. 7235-7241, 2007.

[30] J. M. Macák, H. Tsuchiya, and P. Schmuki, "High-aspectratio $\mathrm{TiO}_{2}$ nanotubes by anodization of titanium," Angewandte Chemie-International Edition, vol. 44, no. 14, pp. 2100-2102, 2005.

[31] S. Li and G. Zhang, "One-step realization of open-ended $\mathrm{TiO}_{2}$ nanotube arrays by transition of the anodizing voltage," Journal of the Ceramic Society of Japan, vol. 118, no. 1376, pp. 291-294, 2010.

[32] Y. Lai, L. Sun, Y. Chen, H. Zhuang, C. Lin, and J. W. Chin, "Effects of the structure of $\mathrm{TiO}_{2}$ nanotube array on Ti substrate on its photocatalytic activity," Journal of the Electrochemical Society, vol. 153, no. 7, pp. D123-D127, 2006.

[33] H. C. Liang and X. Z. Li, "Effects of structure of anodic $\mathrm{TiO}_{2}$ nanotube arrays on photocatalytic activity for the degradation of 2,3-dichlorophenol in aqueous solution," Journal of Hazardous Materials, vol. 162, no. 2-3, pp. 1415-1422, 2009.

[34] L. Zhang, D. D. Macdonald, E. Sikora, and J. Sikora, "On the kinetics of growth of anodic oxide films," Journal of the Electrochemical Society, vol. 145, no. 3, pp. 898-905, 1998. 
[35] Y. Yin, Z. Jin, F. Hou, and X. Wang, "Synthesis and morphology of $\mathrm{TiO}_{2}$ nanotube arrays by anodic oxidation using modified glycerol-based electrolytes," Journal of the American Ceramic Society, vol. 90, no. 8, pp. 2384-2389, 2007.

[36] O. K. Varghese, D. Gong, M. Paulose, C. A. Grimes, and E. C. Dickey, "Crystallization and high-temperature structural stability of titanium oxide nanotube arrays," Journal of Materials Research, vol. 18, no. 1, pp. 156-165, 2003.

[37] W. Chen, Z. Wang, Z. Lin, and L. Lin, "Absorption and luminescence of the surface states in ZnS nanoparticles," Journal of Applied Physics, vol. 82, no. 6, pp. 3111-3115, 1997.

[38] C. Yogi, K. Kojima, N. Wada et al., "Photocatalytic degradation of methylene blue by $\mathrm{TiO}_{2}$ film and $\mathrm{Au}$ particles- $-\mathrm{TiO}_{2}$ composite film," Thin Solid Films, vol. 516, no. 17, pp. 58815884, 2008.

[39] C. Yogi, K. Kojima, T. Hashishin et al., "Size effect of Au nanoparticles on $\mathrm{TiO}_{2}$ crystalline phase of nanocomposite thin films and their photocatalytic properties," Journal of Physical Chemistry C, vol. 115, no. 14, pp. 6554-6560, 2011. 


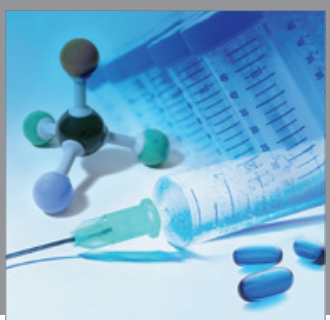

International Journal of

Medicinal Chemistry

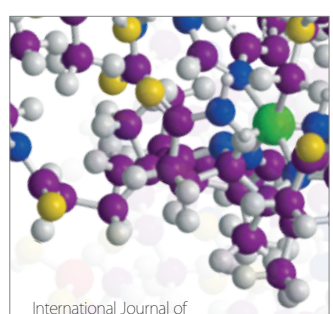

Carbohydrate Chemistry

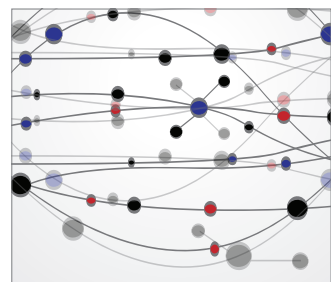

The Scientific World Journal
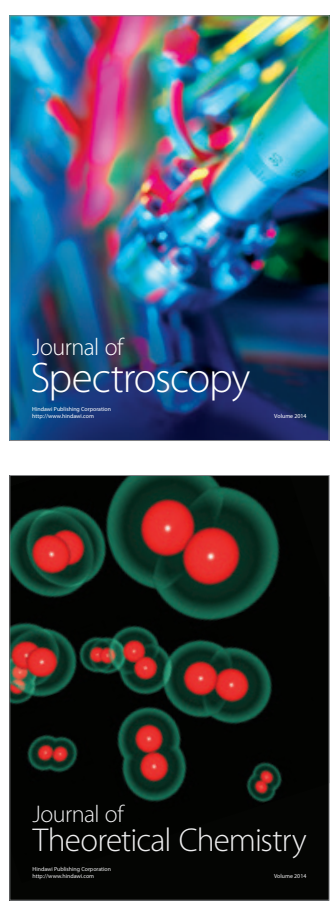
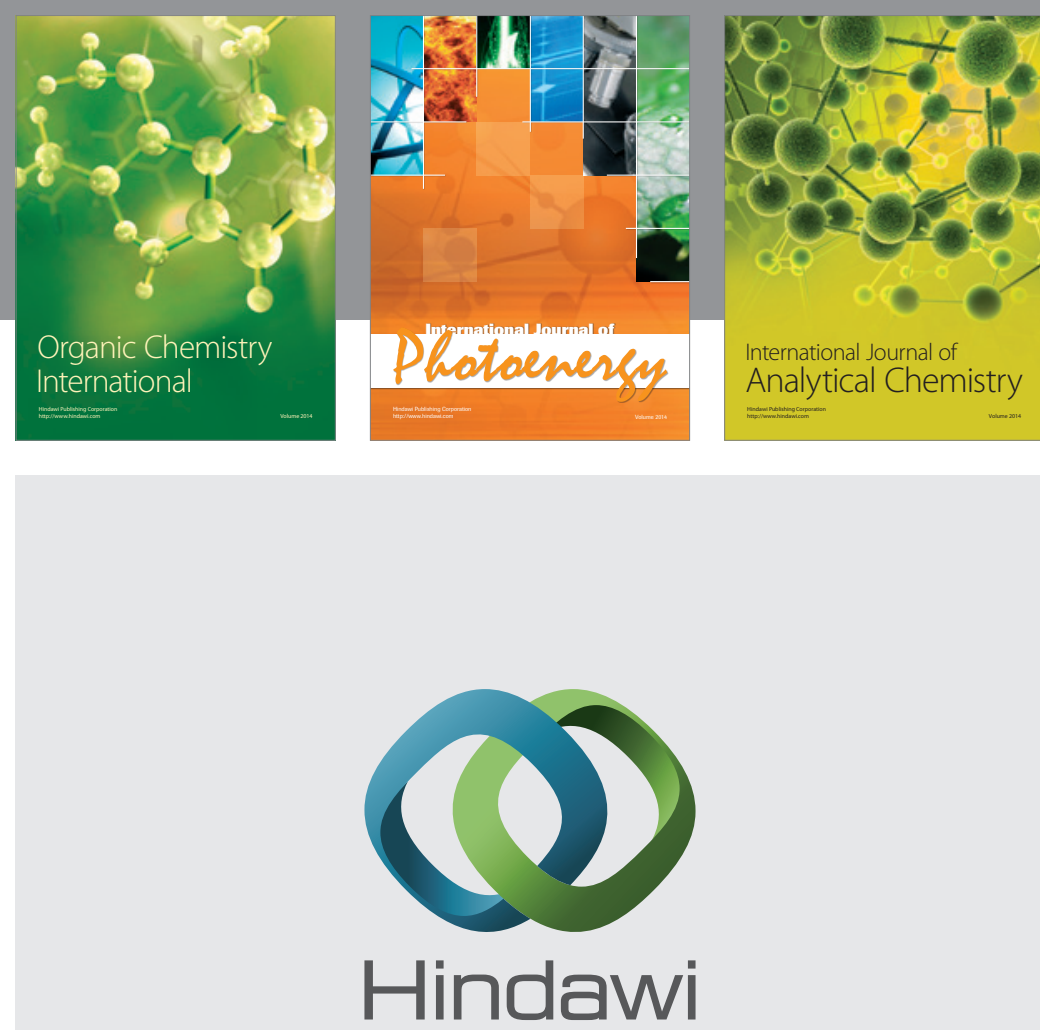

Submit your manuscripts at

http://www.hindawi.com
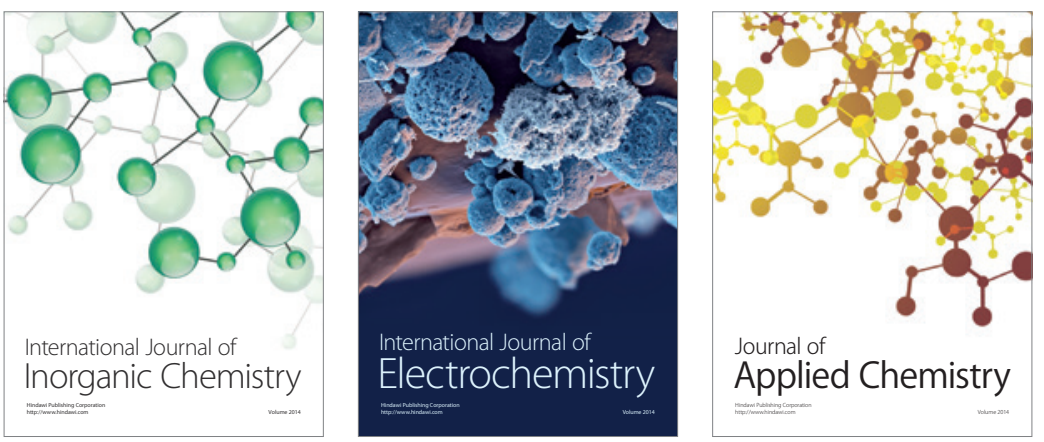

Journal of

Applied Chemistry
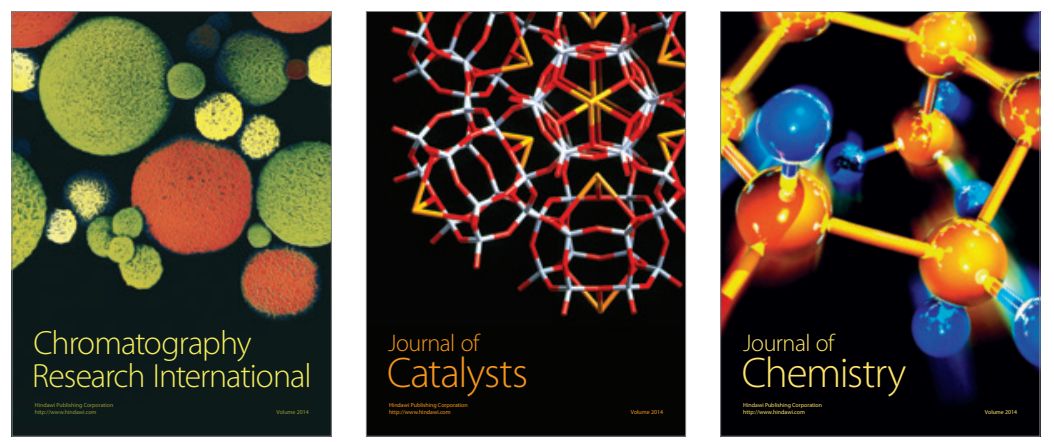
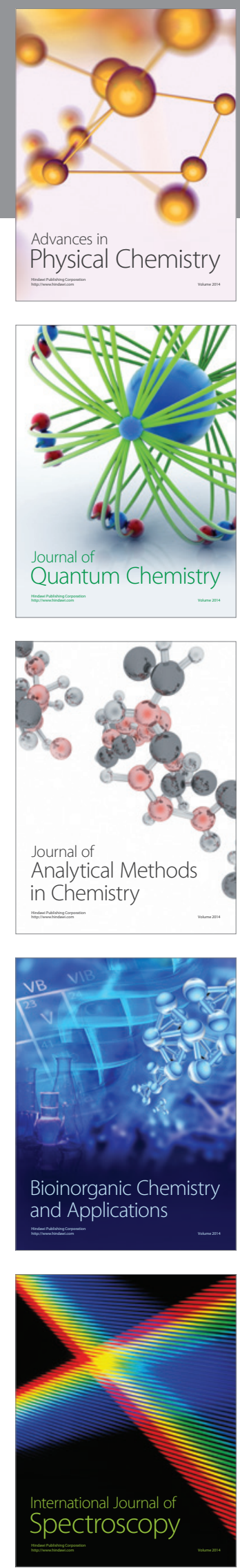